\title{
Seed Refinement in the Harvesting and Post- Harvesting Process
}

\author{
Orobinsky Vladimir Ivanovich \\ $\mathrm{PhD}$ in Agriculture \\ Head of Agricultural Machinery, Tractors and Cars \\ Department, Professor \\ Dean of the Rural Engineering Faculty \\ Voronezh State Agrarian University named after Emperor \\ Peter the Great \\ Voronezh, the Russian Federation \\ e-mail: main@agroeng.vsau.ru \\ Baskhakov Ivan Vasilyevich \\ $\mathrm{PhD}$ in Engineering Sciences, Associate Professor of the \\ Department of Agricultural Machinery, Tractors and Cars. \\ Voronezh State Agrarian University named after Emperor \\ Peter the Great \\ Voronezh, the Russian Federation \\ e-mail: vasich2@yandex.ru
}

\author{
Gievsky Aleksey Mikhailovich \\ $\mathrm{PhD}$ in Technical Sciences, Professor, Department of \\ Agricultural Machinery, Tractors and Cars \\ Voronezh State Agrarian University named after Emperor \\ Peter the Great \\ Voronezh, the Russian Federation \\ e-mail: aleksej.gievskij@mail.ru
}

\author{
Chernyshov Aleksey Viktorovich \\ $\mathrm{PhD}$ in Engineering Sciences, Associate Professor of the \\ Department of Agricultural Machinery, Tractors and Cars. \\ Voronezh State Agrarian University named after Emperor \\ Peter the Great \\ Voronezh, the Russian Federation \\ e-mail: lexa-c@yandex.ru
}

\section{INTRODUCTION}

The failure to abide by the technology of cultivation of grain crops [1], negative climate conditions [13], the increased level of grain injury while processing in the harvest and postharvest period, unsatisfactory quality of the bunker combine heap, high humidity of the growing crop, structural defects of combine harvester threshers, non-optimal operating regime of agricultural machines contribute to quality deviation of future seeds. In Russia, up to $20 \%$ of crop seeds do not meet the requirements of all-Union State Standard P 52325-2005. Grain injury in the harvest and post-harvest processing has a significant impact on the sowing qualities of seeds $[3,4,5$, 13]. Within post-harvest processing air-sieve machines with various features of separation are widely used $[2,6,10,11$, $12]$.

\section{MATERIALS AND METHODS}

The purpose of the research is to determine the technical means used in harvesting and post-harvest grain processing, as well as the optimal regimes of their operation since it ensures minimal injury to grains and the best sowing qualities of seeds.

The bunker combine grain heap consists of small, biologically inferior, crushed, underdeveloped and injured grains, as well as lightweight, small and large weeds. The material selected from the combine bunker consists of a number of components that are shown in Fig. 1.

Keywords - grain, seeds, grain heap, harversting, post-harvest processing, injury, inferior grain. 


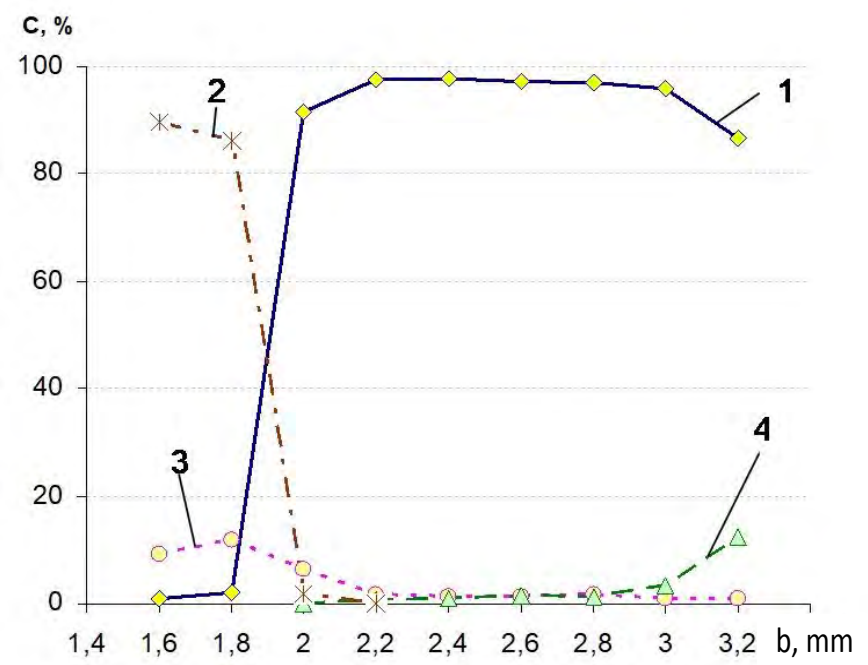

1-whole grain; 2-small impurities; 3-crushed grain; 4 - large impurities

Fig. 1. The composition of the components (C) of the bunker grain heap of winter wheat (DON-93 variety) in terms of the size (b) of throughs of the sorting siev:

The analysis of Fig. 1 indicates that the bunker heap consists mainly of whole grains and that is $74.1 \%$ at an average. Sieves with the $2 \mathrm{~mm}$ through size or more have more than $86 \%$ of the main crop as a result. The second largest component of the bunker is lots of small impurities that reaches an average of $19.7 \%$. In small fractions there are more than $86 \%$ of such weeds but the sieve with the $2 \mathrm{~mm}$ through size separates them completely. Ground grain averages $3,9 \%$ of the total bunker heap. It is found in all factions. The $2.2 \mathrm{~mm}$ and more size of the sieve throughs gives not more than $1.6 \%$. Large impunities are the least numerous component in the bunker heap. They are only about $2.3 \%$. The largest number of large impurities is found when using the $3.2 \mathrm{~mm}$ sieve.

Qualitative indicators of the grain heap of winter wheat (DON-93 variety) in relation to the size of the throughs of the sorting sieve are shown in Fig. 2.

The analysis of Fig. 2 shows that it is advisable to use grain as crop seeds processed by sorting sieves with the 2.6 through size or more. The selected fraction is $84 \%$ in the weighted average value. In addition to the above, the thousand-kernel weight is $43.3 \mathrm{~g}$, the level of grain injury is $49.95 \%$, and the laboratory germination of seeds is $88.25 \%$. Low sowing qualities in this case are explained by increased grain injury. If the seed fraction is produced at the earliest stage of post-harvest processing of grain heap, it will allow to remove all the small weeds and $35.26 \%$ of crushed grain.

The grain that is crushed, injured, biologically inferior or with glumes, as well as weeds, especially small, are a favourable environment for the habitat and reproduction of pests. This has been proven through the study of the intensity

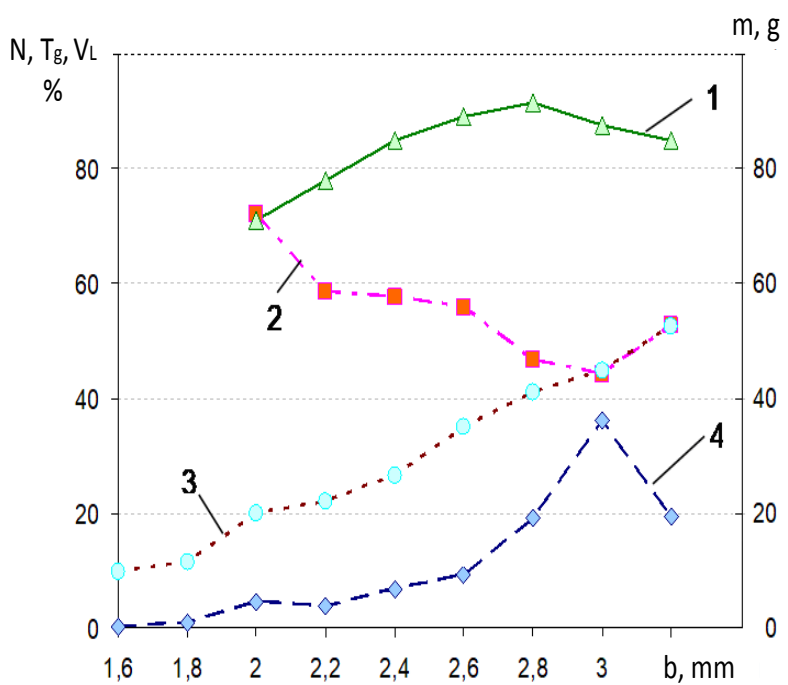

1-laboratory germination of seeds $\left(\mathrm{L}_{\mathrm{G}}\right) ; 2$ - grain injury $(\mathrm{GI})$ 3- thousand-kernel weight (m); 4 - quantity of the produced grain

Fig. 2. The qualitative indicators of the bunker grain heap of winter wheat (DON-93 variety) in terms of the size (b) of throughs of the sorting sieve

of respiration of various components of the grain heap. It was found that this parameter during the 15 days' storage period was 1.8 times and 1.9 times higher respectively in crushed and underdeveloped grains in comparison to whole grains. Meanwhile, the amount of fungal microbial flora was 12 times higher in comparison to the proper developed grain material.

Biologically inferior grains have a smaller thousand-kernel weight and they are less dense. The spread in values of individual grains is explained by the peculiarities of physiological development. The number of biologically inferior grains depends on weather and climate conditions, as well as on the compliance with the technology of cultivation, timing and methods of harvesting. The thousand-kernel weight varies as it depends both on the plant and on the position of grains in the grain head. Research have shown that the grain heap under the post-harvest processing in the Chernozem region consists of biologically inferior grains that ranges from 5.5 to $14.9 \%$ on average. Harvesting in the complete ripeness phase reduces this parameter. If there is increased irregularity of ripening of the plants on the field, it is necessary to use separate cutting. Under the condition due to nutrients coming from the stems the biological ripening of the grain takes place in the windrow. The control hand threshing of the selected sheaves showed that the number of biologically inferior grains is not more than $1 \%$.

Even small keeping period of the grain heap with biologically inferior and crushed, injured grains leads to deterioration of both sowing and commodity qualities. It is explained by the fact that microorganisms secrete metabolic by-products when developing. It causes the formation of 
putrid and musty smell, amino acids and alcohols. Amines are highly toxic substances belonging to the group of cadaveric alkaloid. Methyl and ethyl alcohols destroy the seed bud, which loses its ability to germinate. Unpleasant, persistent, musty smell is observed after the processing of grain into flour and even after the preparation of bakery products. It is proved that large grains are exposed to injuries by microorganisms less than small fractions. It is observed frequently in case of high humidity of grain heap. For example, after a month storage period $3.2 \mathrm{~mm}$ grain fractions were infected by $34.6 \%$, while $1.6 \mathrm{~mm}$ grain fractions were infected by $67.7 \%$, and in 2 months it was 40.3 and $73.9 \%$ respectively.

Consequently, it results in releasing a lot of heat as the injured seeds breathe intensively, growing moldy and eventually fire fang. Moreover, microorganisms develop rapidly in such a heap. All this leads to the decrease in seed germination.

The number of injured grains in the initial heap depends on the construction design of combine harvester threshers, their modes of operation, periods and methods of harvesting, as well as the physical and mechanical properties of the grain at the time of threshing such as humidity. To get high-quality seeds threshing should be carried out when moisture content of the grain is no more than $18 \%$. The change in the level of crushing grains while harvesting winter wheat of Severodonskaya variety depends on its moisture content and method of harvesting as it is shown in Fig. 3.

The analysis of Fig. 3 shows that the crushing of grains with less moisture content increases. This is due to the fact that the dry grain has a bigger stress crack potential when it is processed.

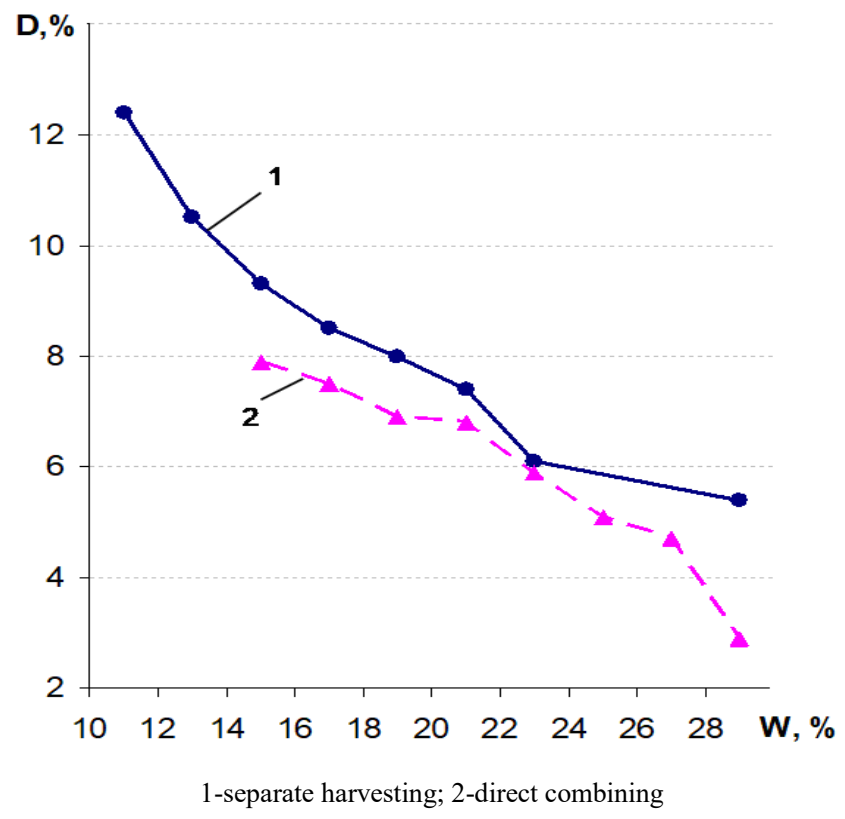

Fig. 3. The change in the level of crushing grains while harvesting winter wheat of Severodonskaya variety depending on its moisture content and method of harvesting
The change in the total micro injuries and the injuries of the grains when harvesting winter wheat of Severodonskaya variety depends on its moisture content and method of harvesting.

The analysis of Fig. 4 shows that direct combine harvesting method decreases injuries of grains when there is a less level of moisture content. Therefore, it is advisable to carry out harvesting when the grain moisture content is low. In the process of separate harvesting with grain moisture content equal to $17 \%$, the trend remains, and then the injury of grains increases slightly.

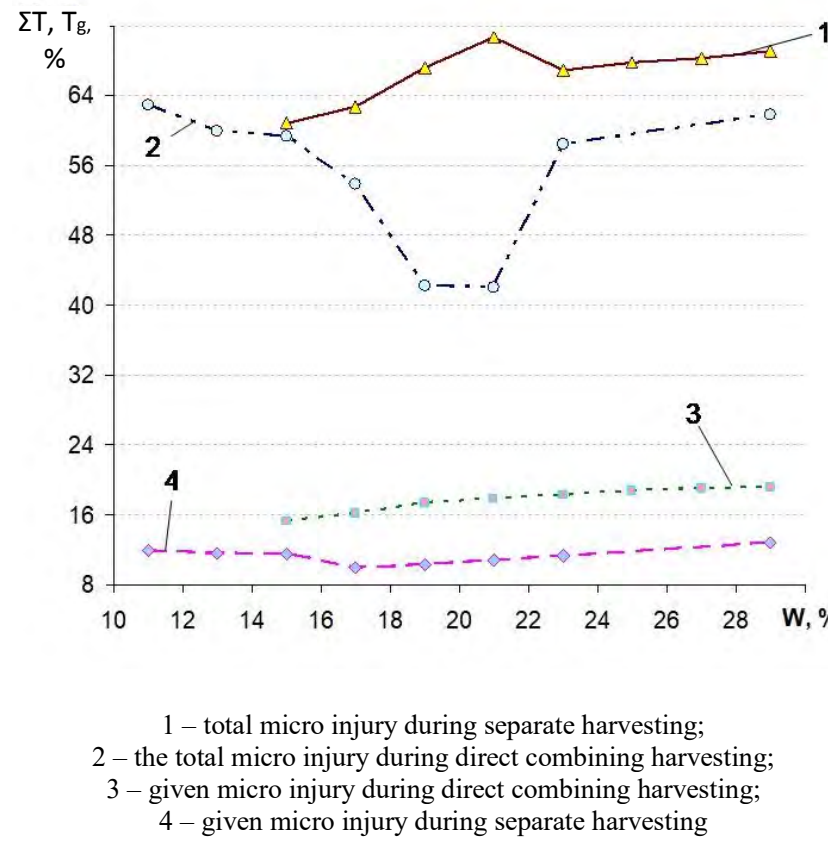

Fig. 4. The change in the total micro injuries and the injuries $(\Sigma T)$ of the grains $(\mathrm{Tg})$ when harvesting winter wheat of Severodonskaya variety depending on its moisture content and method of harvesting

The changes in laboratory germination of the seeds during harvesting of winter wheat of Severodonskaya variety depending on the grain moisture content and harvesting method is presented in Fig. 5.

The analysis of Fig. 5 showed that with separate cleaning as the material dries, the quality of crop seeds increases. When reaching $16 \ldots 18 \%$ grain moisture laboratory seed germination is maximum. Further drying of the material leads to some decrease in sowing qualities. Through direct harvesting with a decrease in grain moisture at the time of threshing, the laboratory germination of seeds increases, reaching the maximum value of $92.1 \%$ with the humidity of $14.0 \ldots 16.0 \%$.

In general, the analysis of Fig. 3-5 showed that the same moisture content of the grain at the time of threshing, higher sowing qualities of seeds were achieved through separate harvesting, since the grain is more homogeneous in terms of moisture.

Grain injury during harvesting depends to a greater extent on the design and operating modes of combine harvester threshers. At present, both drum or classical and rotary 
threshing and separating devices are used in agricultural production. In order to identify the advantages of one of the types of combine harvester threshers, relevant studies were carried out (table. 1).

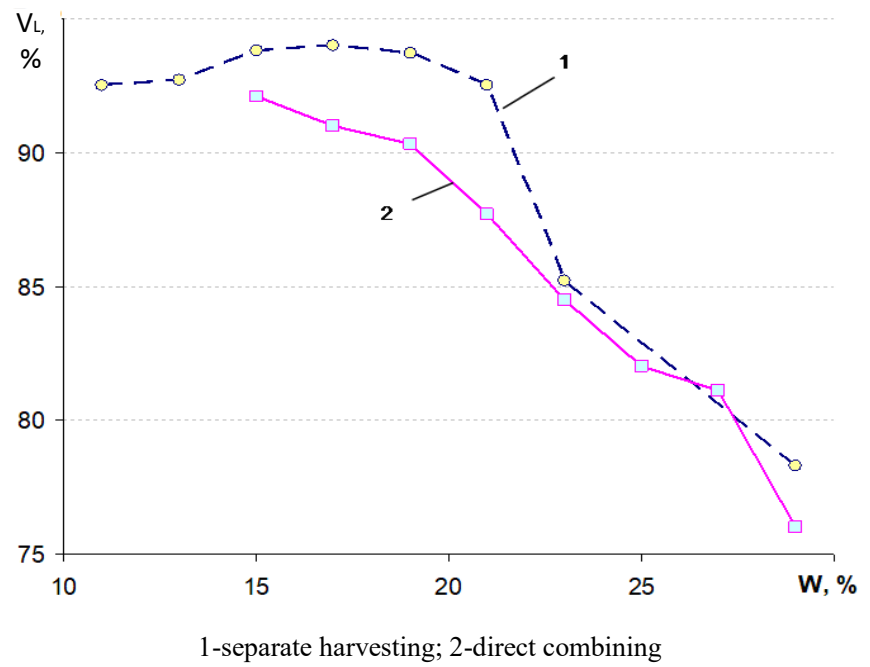

Fig. 5. The changes in laboratory seed germination $\left(V_{L}\right)$ during harvesting of winter wheat Severodonskaya variety according to the grain moisture content and method of harvesting

It should be noted that the combination of friction and impact force the grain mass is exposed to in the rotary threshing and separating devices allows you to set a soft threshing mode, which reduces the injury of grains and increases the sowing qualities of seeds. Table analysis. 1 shows that the classical combine harvester threshers gives a grain heap of less quality. The amount of the whole grain after the rotary threshing-separating device was $2.53 . . .4 .11 \%$ more, and crushed in 2.2..13.41 times less than after the drum alternatives. In the meantime, the laboratory germination of seeds is higher by $1.7 \ldots 4.0 \%$ than in the heap of the classic combine harvest threshers. Working at the same speed, the drum and the rotor $\left(980 \mathrm{~min}^{-1}\right)$ produce different amount of whole grains. The rotary threshing-separating device was $3.71 \%$ more efficient, and the number of crushed grains and grains with glumes is less in 2,20 and 1,51 times respectively. While the laboratory germination of seeds is $1.7 \%$ higher than that of the classical alternatives. Consequently, the replacement of drum harvester threshers by rotary ones will improve the quality of the grain, facilitate its post-harvest processing and create favourable conditions for the production of certified seeds.

Specialized machines and equipment used in grain harvesting allows separating the grain heap according to the grain size, aerodynamic properties and density. The technology of post-harvest grain processing should be implemented through the arranged order that contributes to removing weeds and biologically inferior grains to ensure the required quality of seeds with the least amount of mechanical effects on them.
TABLE I. THE QUALITY OF THE GRAIN PROCESSED BY COMBINE HARVESTER THRESHERS OF JOHN DEERE COMPANY WITH VARIOUS TYPES OF THE THRESHING AND SEPARATING DEVICE

\begin{tabular}{|l|c|c|c|c|}
\hline \multirow{2}{*}{\multicolumn{1}{|c|}{ Indicators }} & \multicolumn{3}{|c|}{$\begin{array}{c}\text { The type of threshing and separating } \\
\text { device of the combine }\end{array}$} \\
\cline { 2 - 5 } & drum & \multicolumn{2}{|c|}{ rotary } \\
\hline Drum (rotor) speed, min ${ }^{-1}$ & 980 & 550 & 840 & 980 \\
\hline $\begin{array}{l}\text { The amount of grains in the given } \\
\text { grain heap, \%: }\end{array}$ & 92.74 & 96.85 & 95.27 & 96.45 \\
$\quad$ - whole grains & 6.17 & 0.46 & 2.62 & 2.80 \\
$\quad$ - crushed grains & 0.92 & 2.56 & 2.05 & 0.61 \\
\hline - grains with glumes & & & & 0.14 \\
\hline $\begin{array}{l}\text { The amount of weeds, \% } \\
\text { Laboratory seed germination, \%: } \\
\quad \text { - when threshed by the combine }\end{array}$ & 93.0 & 97.0 & 96.0 & 94.7 \\
harvester & 100 & 100 & 100 & 100 \\
\hline
\end{tabular}

The recommended thousand-kernel weight of wheat should be $40 \ldots 50 \mathrm{~g}$, which also depends on its type and variety. Larger seeds have higher strength to grow and a higher level of nutrients necessary for the formation of root and leaves. Therefore, during the post-harvest processing it is necessary to select the most complete and homogeneous grains. The most productive way to identify biologically inferior grain is in the aspirating channel of grain-cleaner macines on the base of their aerodynamic properties. And the air flow speed in the second aspirating channel should be at least $8 \mathrm{mps}[7,8,9]$.

Exploring the fractional technology of post-harvest grain processing will allow to receive more high-quality seeds. It is necessary to remove small and undeveloped grains from the grain heap at the earliest stage of the processing by means of grain cleaning machines, while biologically inferior grains should be removed through the increasing of the air flow in the second aspirating channel. The results of research on the influence of the air flow speed and the size of the throughs of sorting sieve sheets on the laboratory germination of seeds are shown in figure 6.

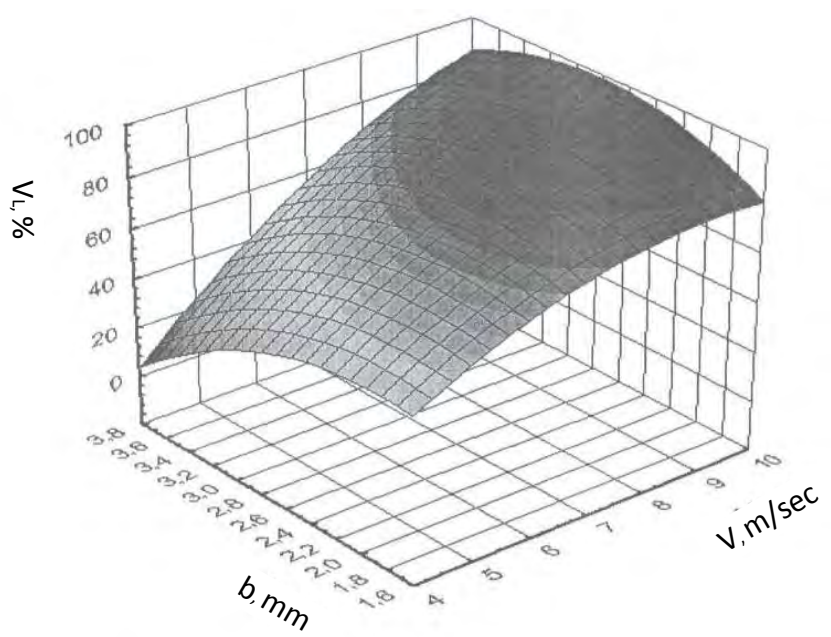

Fig. 6. The influence of the air flow speed $(V)$ and grain size $(b)$ on laboratory seed germination $\left(V_{L}\right)$ 


\section{CONCLUSION}

Summarizing the results of the research, we can conclude that in order to have high-quality seeds, it is necessary to reduce the level of grain injury during the harvesting and post-harvest processing. To do this, you need to use rotary combine harvester threshers and clean the grain heap immediately as it is transported to the elevator to remove weeds, crushed and biologically inferior grains. And grain cleaning machines must produce at least three fractions. Cleaned wheat grains need to be sorted through sorting sieves with rectangular throughs $2.4 \ldots 2.6 \mathrm{~mm}$ wide. Small impurities should be removed on the sieve sheets with the cell size of $1.7 \mathrm{~mm}$. Biologically inferior grains should be removed by increasing the air flow speed to $8 \mathrm{mps}$ in the second aspirating channel. This will lead to a significant reduction in the seed injury and increase laboratory germination.

\section{References}

[1] V. I. Orobinsky, A. M. Gievsky, Ah. Schwartz, I. V. Baskakov, A. V. Chernyshov, "Improving the efficiency of apparatus of exact sowing of small-seed crop", Journal of Fundamental and Applied Sciences, vol. 10 (5S), pp. 1226-1241, 2018

[2] A. M. Gievsky, V. I. Orobinsky, A. P. Tarasenko, A. V. Chernyshov and D. O. Kurilov, "Substantiation of basic scheme of grain cleaning machine for preparation of agricultural crops seeds", IOP Conference Series: Materials Science and Engineering electronic resource, no. 042035, 2018

[3] V. I. Aniskin, V. M. Drincha and I. A. Pehalsky, "Damage to the seed crops during the machining", J. Agrarian science, 1992, vol. 1, pp. $97-$ 105
[4] U. F. Lachuga, A. U. Izmailov and A. N. Ziulin, "High-efficiency resource and energy saving technologies and technical tools of grain postharvest treatment", J. Agricultural machinery and technologies, 2009, vol. 1, pp. 2-9.

[5] V. P. Pyanykh, S. A. Rodimtsev, "Reducing of the grain damage during the threshing", J. Mechanization and electrification of agriculture, 2000, vol. 12 , pp. 4-6

[6] A. P. Tarasenko, V. I. Orobinsky, M. E. Merchalova A. V., Chernyshov and N. N. Sorokin, "Fractionation of Grain Heap on Sieves", J. Agricultural machines and technologies, 2006, vol. 5, pp. 26-29.

[7] F. Shahbazi, S. Valizadeh and A. Dowlatshah, "Aerodynamic properties of Makhobeli, triticale and wheat seeds", Int. Agrophys, 2014, Vol. .28, pp. 389-394.

[8] A. M. Matouk, S. M. Abd El-latif and A. Tharwat, "Aerodynamics and mechanical properties of some oil producing crops”, J. Agric. Sci.,2008, vol. 33, pp. 4195-4211.

[9] K. D. Astanakulov, Y. Z. Karimov and G. Fozilov, "Design of a Grain Cleaning Machine for Small Farms", Ama-Agricultural Mechanization in Asia Africa and Latin America, 2011, vol. 42, no. 4. pp. 37-40.

[10] X. P. Liu, Y. L. Zhang and D. Yang, "Finite Element Analysis of 5XF150/180 Type Grain Cleaning Machine”, 2014, pp. 112-118. [International Conference on mechanics Science and Control Engineering (MSCE 2014), 2014]

[11] J. Paliwal, D. S. Jayas, N. S. Visen and N. D. G. White, "Accessibility of a machine-vision-based grain cleaner", Applied Engineering in Agriculture, 2004, vol. 20, no. 2. pp. 245-248.

[12] V. E. Saitov, R. F. Kurbanov and A. N. Suvorov, "Assessing the Adequacy of Mathematical Models of Light Impurity Fraction in Sedimentary Chambers of Grain Cleaning Machines", 2016, vol. 150. pp. 107-110. [2nd International Conference on Industrial Engineering (ICIE-2016)]

[13] V. I. Orobinsky, "Influence of microorganisms and keeping period on sowing qualities of seeds", J. Mechanization and electrification of agriculture, 2000, vol. 12, pp. 4-6. 